\title{
INFLUENCE OF MANUFACTURING METHODS ON THE TRIBOLOGICAL PROPERTIES OF RAPESEED OIL LUBRICANTS
}

\author{
Juozas Padgurskas ${ }^{1}$, Raimundas Rukuiža ${ }^{2}$, Algirdas Meškinis ${ }^{3}$, \\ Raimondas Kreivaitis ${ }^{4}$, Bronislovas Spruogis ${ }^{5}$ \\ 1,2,3,4 Institute of Power and Transport Machinery Engineering, Aleksandras Stulginskis University, \\ Akademija, Kaunas District, Lithuania \\ ${ }^{5}$ Dept of Transport Technological Equipment, Vilnius Gediminas Technical University, Vilnius, Lithuania
}

Submitted 14 May 2014; resubmitted 14 October 2014; accepted 4 January 2015; first published online 15 June 2015

\begin{abstract}
Tribological properties of rapeseed oils manufactured and processed by different methods and modified by the anti-wear additives were analysed. Tribological tests presented that unrefined rapeseed oil has better wear resistance compared to refined oil. Modification of rapeseed oil with $2 \%$ of special biological anti-wear additives has the greatest influence on refined rapeseed oil. Chemical analysis shows that refinement removes acids from oil. Refinement and lower acidity allows more efficient operation of special biological anti-wear additives.
\end{abstract}

Keywords: lubricants; biodegradability; rapeseed oil; refinement; anti-wear additives; wear; friction; acidity.

\section{Introduction}

Considering annually increasing amounts of trucks, buses, high power tractors and personal cars, the consumption of mineral-based fuels and lubricants increases as well as environmental pollution. The greatest part of energy consumed in the world is obtained from nonrenewable fossil fuel. The use of this energy source has a negative impact on the environment. Furthermore, fossil fuel resources are intensively decreasing. Therefore, interest in alternative renewable resources is currently growing. Environmentally friendly bio-based lubricants are one of the alternative ways to save fossil resources and decrease pollution (Bartz 2006).

Biological materials are used for production of biological oils. Depending on application, it could be rapeseed, sunflower, flax, palm or other oils. Animal derived materials such as lard, beef tallow, etc. could also be used as a basis for biological lubricants. Biological lubricants have two main advantages: biodegradability and harmlessness. Accidental lubricant spills or leakage when used in the environmentally sensitive places - such as agriculture, forestry, mining districts, construction sites, water ways and reservoirs - may cause an ecological disaster. Taking this into account, most European countries have set the requirements promoting the use of environ- mentally friendly lubricants. They are environmentally friendly and $80 \%$ biodegradable, while only $15-20 \%$ of mineral oils degrade during the same period (Honary, Richter 2011; Erhan, Perez 2002; CEC 1995).

The use of vegetable oils is encouraged in cases where recycling complex or impossible. Major areas of application are found in the field of transport and power machinery engineering, where biodegradable lubricants have already been put to use or are planned in nearest future. These are boating two-stroke lubricants, hydraulic system oils, engine oils, and rail curve greases. Rapeseed oil has the widest range of application among vegetable oils: hydraulic oils, tractor transmission fluids, metal working fluids, food grade lubes, penetrating oils, chain bar lubes, etc. (Sathwik Chatra et al. 2012).

The possibility to use biological oils in industrial machinery for lubrication is limited due to low thermal and oxidation stability. Oxidation causes polymerization and degradation. During the latter, decomposition products appear which may be volatile, start corrosion and reduce oil lubricating properties. The oxidation rate is determined by temperature, the contact of metals with oil and the amount of water and oxygen in oil. The effect of temperature is great as with its increment by $10^{\circ} \mathrm{C}$, the oxidation rate may rise three times. It is important

Corresponding author: Juozas Padgurskas

E-mail: juozas.padgurskas@asu.lt 
to study new environmentally friendly lubrication materials with higher oxidation stability, which can be used for modification of total loss lubricants. Natural antioxidant extracts can be used as effective natural antioxidants in lubrication applications of rapeseed oil, but its use depends on manufacturing technology and the compatibility with tribological additives (Kodali 2002; Suzuki et al. 2009; Kreivaitis et al. 2013).

Lubrication properties of vegetable oils are strongly related to their chemical structure and content. Vegetable oils are composed of triglycerides, which consist of glycerol and three fatty acids of different chain lengths (Fig. 1). Fatty acids of the triglyceride may be saturated or unsaturated. Oils in fatty acids may be saturated, mono- and polyunsaturated. Furthermore, different fats may be different in their content (Honary, Richter 2011; Erhan, Perez 2002). It is the fatty acid composition of oil that determines its characteristics. The presence of double bonds makes oil liquid but also increases oxidative instability. Oils highly enriched in monounsaturated fatty acids have improved lubricity and an oxidative stability (Menezes et al. 2012).

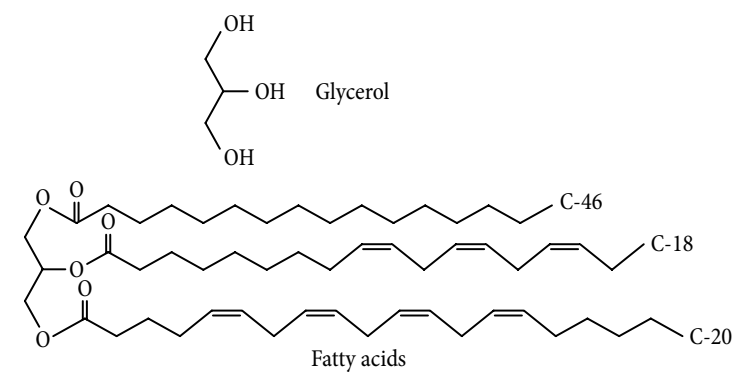

Fig. 1. Structure of triglycerides with varying chain lengths of fatty acids (Menezes et al. 2012)

The hydrocarbon chain in saturated fatty acids does not have double bonds, so it is particularly resistant to oxidation. It is preferred in lubricants to improve their oxidative stability. However, saturated fatty acids with longer hydrocarbon chains increase the pour point of the mixture (Honary, Richter 2011).

The structure and content of vegetable oils is influenced by the manufacturing method. The thermal range of oil manufacturing and refinement change the content of fatty acids and the length of their chains (Kodali 2002; Kreivaitis et al. 2009). Refinement can selectively affect lateral substances by weakening their relationship with fatty acid triglycerides and, thus, remove them from oil. Such lateral substances could be toxic chemicals (heavy metals, pesticide residues, oxidation products, etc.), free fatty acids, dyestuffs (pigments), volatile and other unwanted substances (O'Brien 2008). It should influence tribological properties of biological lubricants. The modification with additives can also change the tribological efficiency of vegetable oils (Padgurskas et al. 2009).

The aim of this research is to analyse tribological properties of rapeseed oils manufactured and processed by different methods and modified by anti-wear additives.

\section{Experimental Details}

The rapeseed oil produced by different extraction, refinement and additive modification was investigated. The following oil lubricants were tested:

- Unrefined Rapeseed Oil of Cold Extraction (UROCE);

- Unrefined Rapeseed Oil of Hot Extraction (UROHE);

- Refined Rapeseed Oil of Cold Extraction (RROCE);

- UROCE, UROHE and RROCE oils modified with special 'green' anti-wear additive 5034A produced by Lubrizol Company for biological lubricants ( $2 \%$ concentration).

The research was carried out with the four ball friction test machine MAST-1 (Fig. 2) assembled and modernised at Aleksandras Stulginskis University. The balls $12.7 \mathrm{~mm}$ in diameter were made of $100 \mathrm{Cr} 6$ bearing steel $(E=21.98 \cdot 10 \mathrm{MPa} ; v=0.3)$. The testing procedure was adapted from the standard DIN 51350-3:2015-03.

The following other equipment was used in the research: scales KERN EG420-3NM; microscope MBI-6; ultrasonic bath BANDELIN/Sonorex Digitec - type DT 1034; thermocouple Pico TC-08; and spectroscope OCEANOPTICS FL 4000.

Tests with four-ball test machine were performed by reinforcing three balls at the bottom of the oil container and rotating one ball with a motor shaft spindle. Circular wear spot appeared on three balls in the oil container and wear scar in the form of a bar appeared in the shaft spindle-seated ball. Wear reducing efficiency of lubricants was evaluated according to wear spots measured with a microscope. The ability of oil to reduce friction losses was estimated by measuring of friction torque during the tests. The tests were carried out at two different loads: $150 \mathrm{~N}$ and $300 \mathrm{~N}$.

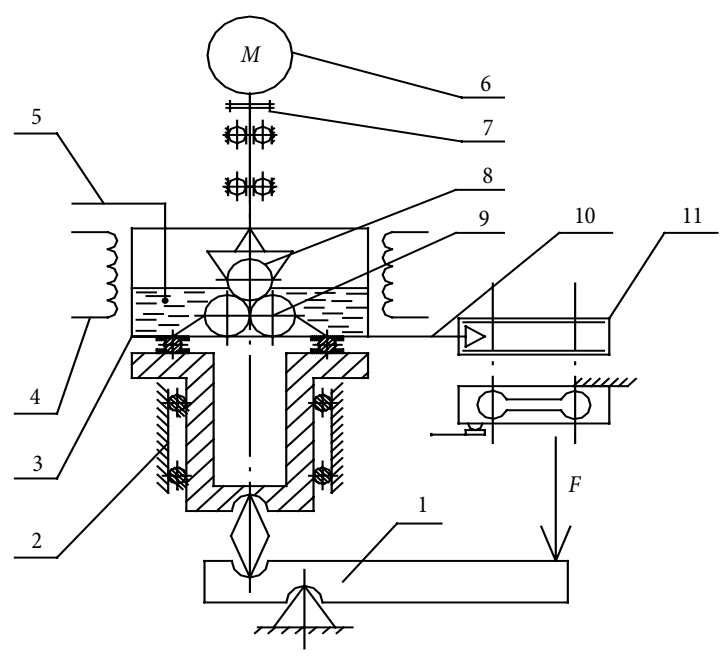

Fig. 2. Schematics of the Four-Ball Tribotester MAST-1: 1 - load transfer lever; 2 - vertical centre bearing; 3 - oil sample compartment; 4 - oil heater; 5 - thermocouple; 6 - electric motor; 7 - clutch; 8 - upper rotary ball; 9 - lower stationary balls; 10 - torque transfer lever; 11 - force transducer 
Physical and chemical parameters of the lubricants were measured:

- acid value - according to the standard EN ISO 660:2009;

- kinematic viscosity - according to the standard EN ISO 3104+AC:2000;

- viscosity index - according to the standard ISO 2909:2002.

In addition, wear surface studies were performed with optical microscopy as well as spectroscopic oil measurements of light absorption and permeability.

\section{Results and Discussion}

\subsection{Wear Resistance Properties of Investigated Oils}

The most important tribological property of a lubricant is the ability of oil to ensure lower wear of friction surfaces. The results of wear spot measurements show that unrefined rapeseed oil has better wear resistance compared to refined oil (Fig. 3a). Besides, hot extraction is superior for tribological properties of rapeseed oil compared to cold extraction technology. The oils show similar trends of wear resistance properties at both loads $150 \mathrm{~N}$ and $300 \mathrm{~N}$.

Further experiments of rapeseed oil with anti-wear additives showed that the impact of the additives on tribological properties of rapeseed oil is very different compared to the results of pure oil testing (Fig. 3b). The additives have the biggest wear reducing influence on refined rapeseed oil; they can decrease the wear almost twice. Most probably, the refinement eliminates the lateral substances, which can disturb the positive impact of the additives. Cold extraction leaves more healthy nutrient substances in oil (O'Brien 2008), but such substances have no value for lubrication. This also confirms that

a)

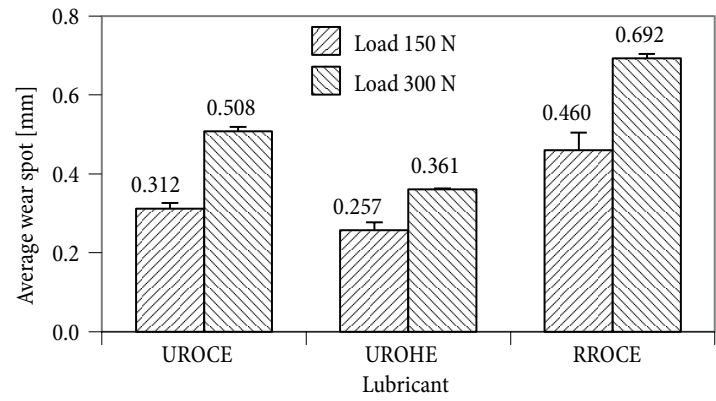

b)

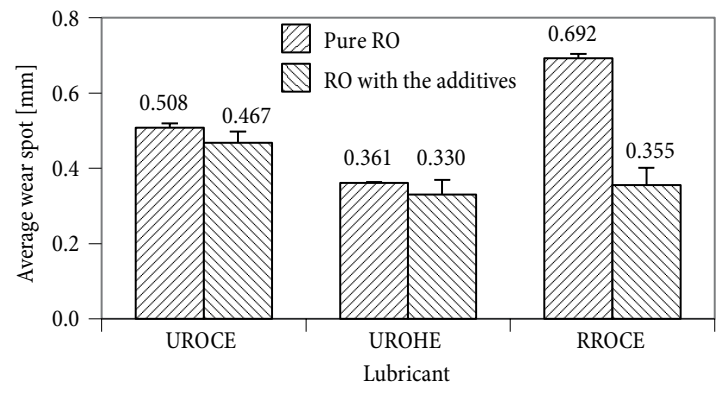

Fig. 3. Wear measurement data testing: a - pure rapeseed oil at loads of $150 \mathrm{~N}$ and $300 \mathrm{~N}$; b - rapeseed oil modified with anti-wear additives at $300 \mathrm{~N}$ better wear inhibiting properties of oil can be achieved by hot extraction.

Microscopic analysis of wear traces presented different surface decay depending on different lubricants. Wear spots had abrasion scars, adhesion and gripping traces. After the operation of friction pairs at the load of 150 N, wear spots (Fig. 4) differed not only in size, but also in the character of surface interaction.

Unrefined oils (UROCE and UROHE) caused some adhesion of counter body and refined oil RROCE caused abrasion to a very smooth surface. The increase of load to $300 \mathrm{~N}$ also caused changes of the surface wear character (Fig. 5). More abrasion scars emerged on the surfaces and the size of wear spot increased dramatically. It was interesting that the use of specialised additives reduced the size of a wear spot (Fig. 6), but did not protect the friction surfaces from deep scars and non-regular abrasion. The additives in UROCE oil caused deep scars in the centre of the spot and in UROHE oil - uneven friction surface. Modification with additives of refined RROCE oil reduced the size of a spot and depth of scars. There were also some signs of a new material on friction surface, which could be wear-protective layer of the additive.
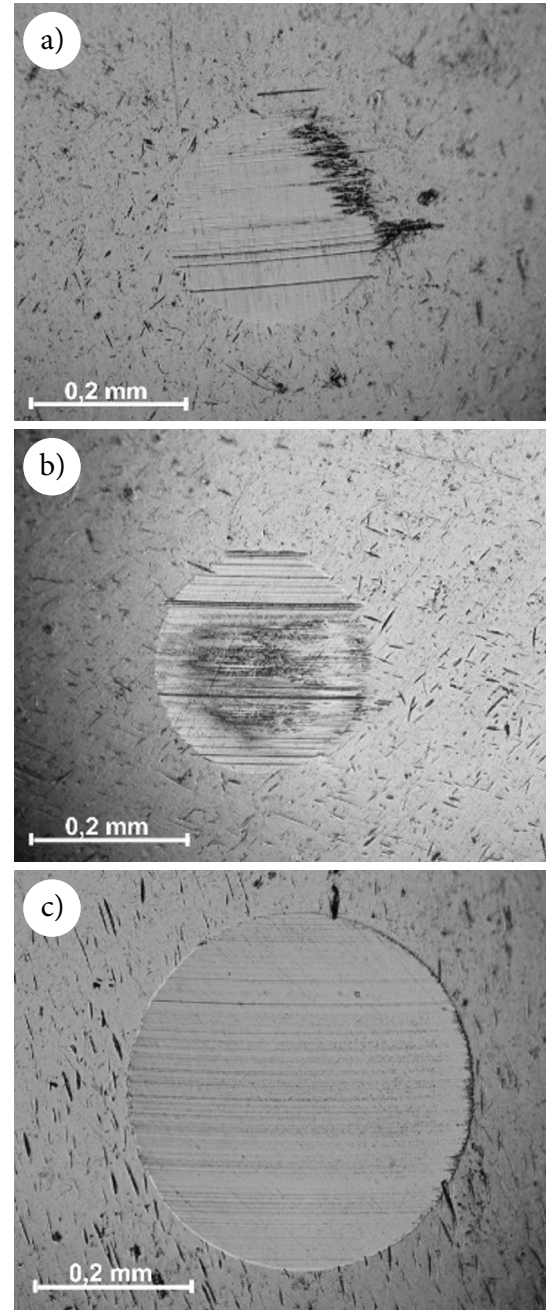

Fig. 4. Wear traces on the balls after operation of different rapeseed oils at the load of $150 \mathrm{~N}$ : a - UROCE; b - UROHE; c - RROCE 

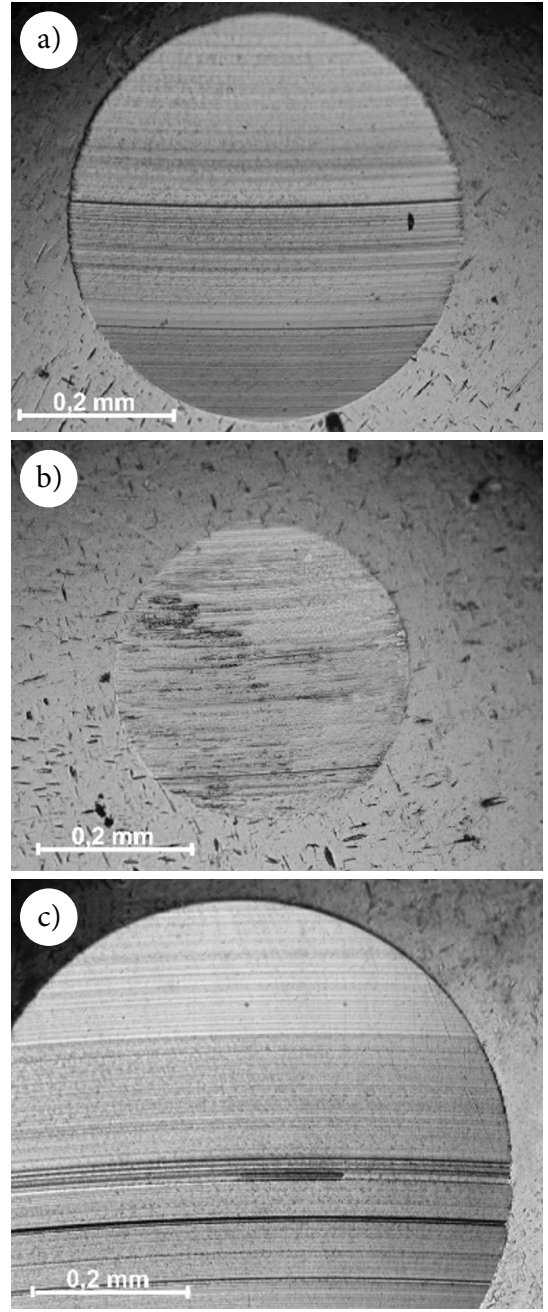

Fig. 5. Wear traces on the balls after operation of different rapeseed oils at the load of $300 \mathrm{~N}$ : a - UROCE; b - UROHE; c - RROCE

\subsection{Friction Torque Behaviour During the Tests}

The measurements of friction torque during the operation of friction pairs presented higher friction force when using the refined rapeseed oil RROCE (Fig. 7a, b), which is in accordance with the wear measurements (Fig. 3a).

The double increase of friction coefficient once loading was increased up to $300 \mathrm{~N}$ (Fig. 7b) was also expected. However, the difference of the friction coefficient between refined (RROCE) and unrefined oils (UROCE and UROHE) at $300 \mathrm{~N}$ was not as significant compared to wear measurement values. The measurement of oil temperature during the tests (Fig. 8) confirmed that at $300 \mathrm{~N}$, friction and energy losses for all 3 kinds of rapeseed oils were similar.

It is interesting that at $150 \mathrm{~N}$, refined oil RROCE showed the increase of the friction coefficient at the end of the tests (Fig. 7a) and at $300 \mathrm{~N}$, it was higher at the beginning and stabilised during the further operation (Fig. 7b). The surface illustrated in Fig. 4c shows that at the end of operation at $150 \mathrm{~N}$, very smooth friction surface was formed, which could be unfavourable for the stable boundary layer of the lubricant.
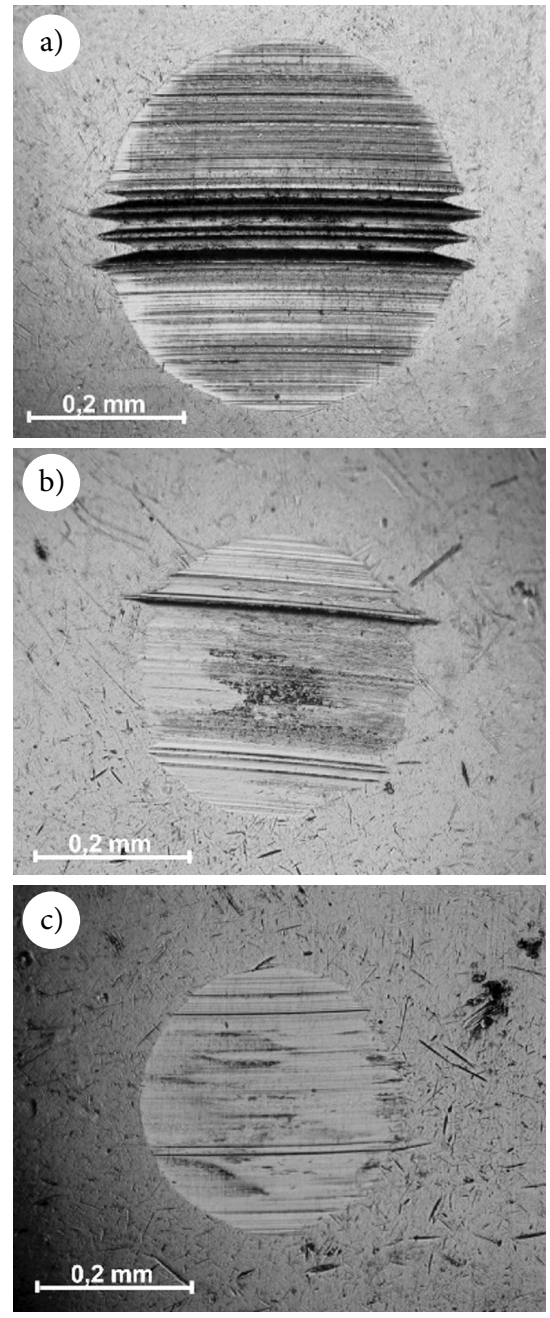

Fig. 6. Wear traces on the balls after operation of different rapeseed oils with additives at the load of $300 \mathrm{~N}$ : a - UROCE; b - UROHE; c - RROCE

The behaviour of friction torque when using the additives (Fig. 7c) confirmed that the most stable friction torque of UROHE oil passed to the lowest wear results of this oil. Higher picks of the friction coefficient of UROCE oil could cause higher wear at the operation with this lubricant. This could be related to very deep scars on wear spots seen in Fig. 6a. When samples were operated with refined oil RROCE, the friction coefficient was unstable and reached the highest values, which caused the increase of temperature (Fig. 8). However most probably, this higher temperature was more advantageous for efficient operation of special oil additives ensuring lower abrasion of the surface. Besides, the jumpy friction torque graph of the RROCE test shows of the formation of protective anti-wear layer when using additives in refined oil.

In summary, the tribological efficiency of special additives is clear only evaluating the wear decreasing properties of modified oils. Additives have very limited impact on the value of the friction coefficient. Only UROCE oil modification with additives decreased the friction torque of this lubricant. 

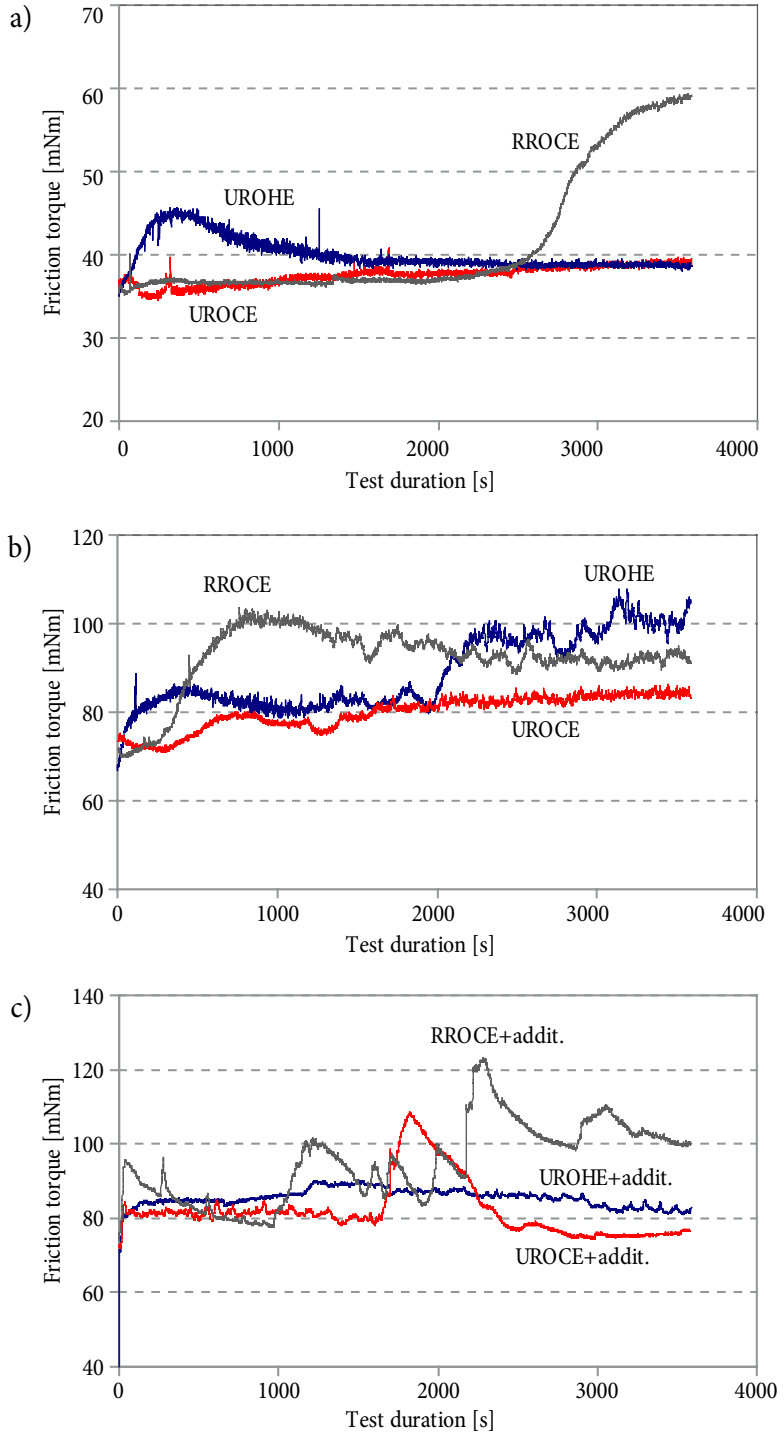

Fig. 7. The friction torque variation during the tests: a - pure rapeseed oils at the load of $150 \mathrm{~N}$; b - pure rapeseed oils at the load of $300 \mathrm{~N}$; c - rapeseed oils with $2 \%$ additive 5034A at the load of $300 \mathrm{~N}$

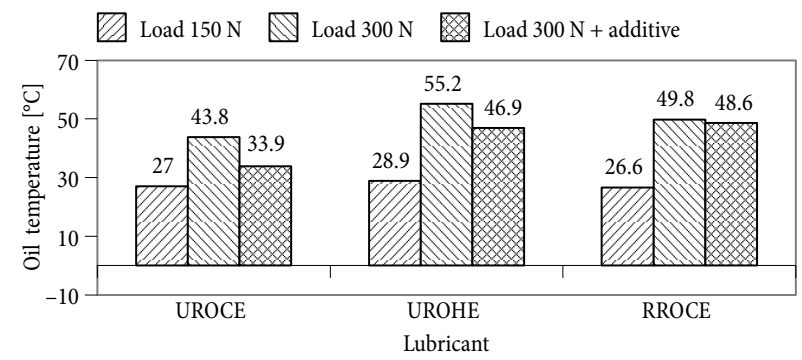

Fig. 8. Increase of oil temperature during tribological tests of rapeseed oil

\subsection{Chemical and Physical Properties of the Lubricants}

The following measurements of chemical and physical properties of the lubricants were carried out: viscosity, density and acid number (acid value). The results are presented in Table.

There is a slight difference in viscosity and density of differently produced oils, but the acid value varies significantly. Hot extraction increases the acid number compared to cold extraction and both non-refined oils UROCE and UROHE have a clearly higher acid number compared to refined oil. This shows that refinement removes acids from oil.

However, higher acidity has a positive impact on tribological properties of rapeseed oil. Acids activate the surfaces and consequently increase the corrosion. The oxide layer formed on the friction surface has higher hardness and this could explain the lower wear when using oils with higher acidity. Some fatty acids (i.e. oleic acid) increase acidity and stability of the oxidation layer thus allowing the formation of a tribochemical layer as an adsorption layer of polar molecules separating the contacting surfaces (Kreivaitis et al. 2009). Such fatty acids could be used as wear protective additives in vegetable oils (Kreivaitis et al. 2009; Zhan et al. 2004; Cao et al. 2000). However, excess acidity can cause faster oil degradation, which has a negative influence on metal surfaces and seals. When acidity is too high, the wear is also more pronounced.

The situation changes if special biological additives are used in refined oil. In that case, fatty acids do not compete with the investigated additives in building the absorption layer (Kreivaitis et al. 2009) and lower acidity of refined oil is more advantageous for operation of such additives.

Spectroscopic oil measurements of light absorption show the length of waves absorbed by one oil or another. It shows the presence of various substances in differently manufactured oils. This could cause differences in wear results of tested lubricants. The graphs of absorption test in Fig. 9a and permeability test in Fig. 9b show the differences of lubricants contents.

Adsorption of visible radiation in wavelength between $380 \mathrm{~nm}$ and $780 \mathrm{~nm}$ of oils UROCE and UROHE is clearly higher than that of the refined oil RROCE (Fig. 9a). It could be supposed than there are many different substances in unrefined oils, which are removed during refinement. The highest absorption takes place in the wavelength from $360 \mathrm{~nm}$ to $540 \mathrm{~nm}$, which pass the colours up to yellow. The absorption spectra in range of yellow to red (650-690 nm) are also remarkable especially for unrefined oil of cold extraction (UROCE).

Table. Chemical and physical properties of rapeseed oils

\begin{tabular}{cccccccc}
\hline $\begin{array}{c}\text { Rapeseed } \\
\text { oil }\end{array}$ & $\begin{array}{c}\text { Viscosity } \\
{\left[\mathrm{mm}^{2} / \mathrm{s}\right]}\end{array}$ & $\begin{array}{c}\text { Viscosity } \\
{\left[\mathrm{mm}^{2} / \mathrm{s}\right]}\end{array}$ & $\begin{array}{c}\text { Viscosity } \\
\text { index }\end{array}$ & $\begin{array}{c}\rho 40 \\
{\left[\mathrm{~g} / \mathrm{cm}^{3}\right]}\end{array}$ & $\begin{array}{c}\rho 100 \\
{\left[\mathrm{~g} / \mathrm{cm}^{3}\right]}\end{array}$ & $\begin{array}{c}\rho 15 \\
{\left[\mathrm{~g} / \mathrm{cm}^{3}\right]}\end{array}$ & $\begin{array}{c}\text { Acid } \\
\text { number }\end{array}$ \\
\hline UROCE & 34.607 & 7.9788 & +214.5 & 0.9035 & 0.8645 & 0.9198 & 1.3 \\
\hline UROHE & 35.103 & 8.0784 & +214.3 & 0.9071 & 0.8674 & 0.9237 & 2.4 \\
\hline RROCE & 34.357 & 7.9661 & +216.0 & 0.9045 & 0.8648 & 0.9210 & 0.1 \\
\hline
\end{tabular}



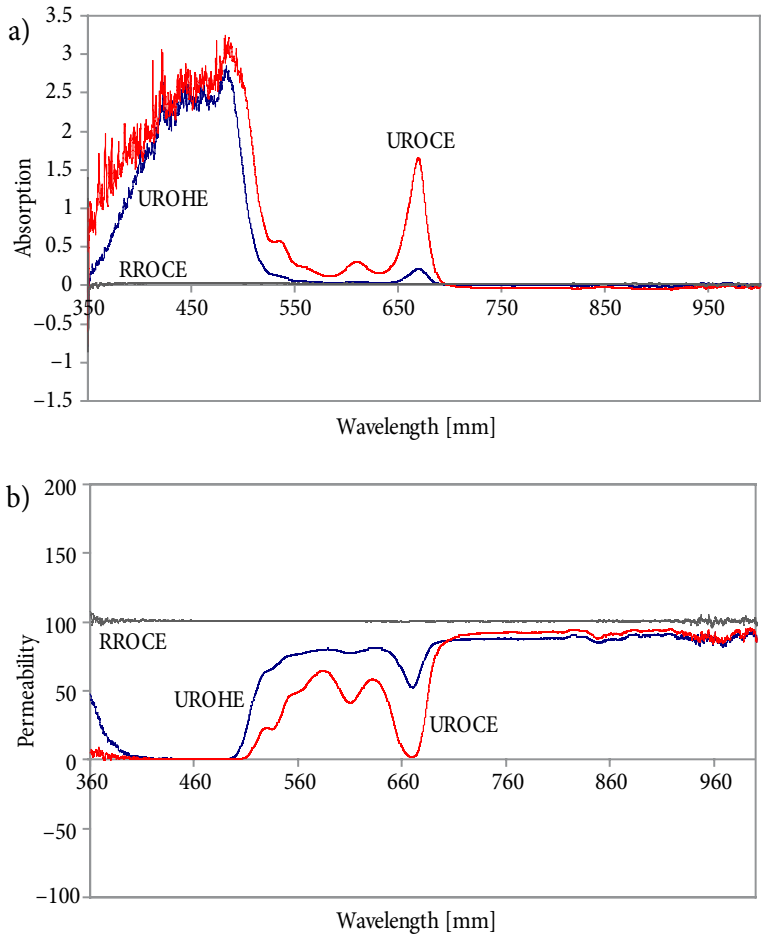

Fig. 9. Light wave spectroscopy analysis of rapeseed oils: $\mathrm{a}$ - absorption; $\mathrm{b}$ - permeability

This means that hot extraction removes some substances compared to cold extraction. Permeability tests (Fig. 9b) confirm the removal of most substances by refinement taking it as reference. The tests confirmed that lower tribological efficiency of special additives in unrefined oils is strongly related to the negative interference of residue substances with the wear resistance mechanism of those additives.

\subsection{Discussion on the Mechanism of Additive Operation}

Efficiency of biodegradable additives is related to the operation of solid lubricant or additive particles in the contact zone of friction surfaces. The performed investigations show that rapeseed oil as an environmentally friendly liquid lubricant can carry 'green additives' (e.g. third body boric acid particles) to provide a mixed lubrication system between contacting surfaces (Fig. 10).

The boric acid powder and canola oil lubricant mixture have a multifunctional lubrication performance, where surfaces are separated by a liquid lubricant film and protected by an additive of micron-scale $(100-700 \mu \mathrm{m})$ boric acid particles (Menezes et al. 2012).

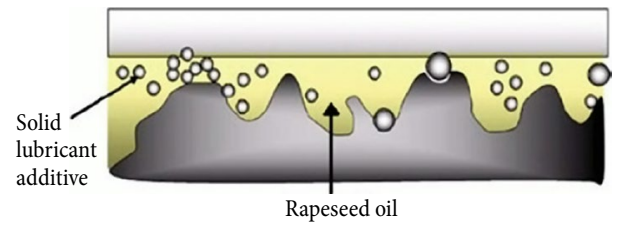

Fig. 10. Green liquid lubricant (i.e. rapeseed oil) carries green solid lubricant additive that provides a mixed lubrication system (Menezes et al. 2012)
The tribological efficiency of special biological additives in refined rapeseed oil should be explained by a similar mechanism of additive operation.

\section{Conclusions}

Tribological tests of wear resistance properties of differently produced rapeseed oils at the loads of $150 \mathrm{~N}$ and $300 \mathrm{~N}$ show that unrefined rapeseed oil has better wear resistance has compared to refined oil. Besides, hot extraction is superior compared to cold extraction technology. Modification of rapeseed oil with $2 \%$ of special biological anti-wear additives has the biggest influence on refined rapeseed oil; it can decrease wear almost twice.

Additives have a very limited impact on the value of friction torque during tribological tests of rapeseed oils. The wavy graph of friction torque shows the formation of protective anti-wear layer when using additives in refined oil.

Oil density and viscosity do not depend on manufacturing method. The chemical analysis shows that refinement removes acids from oil. A higher content of fatty acids causes a lower wear of friction pairs lubricated with unrefined oils. Refinement and lower acidity allow a more efficient operation of special biological additives.

The spectral analysis also confirms that the refinement removes many substances from oils. If anti-wear additives are used, the removal of lateral substances is advantageous for tribological properties of refined oil.

\section{Acknowledgements}

This research was supported by EU FP7 IRSES project Oil\&Sugar (FP7-PEOPLE-2011-IRSES-295202) grant.

\section{References}

Bartz, W. J. 2006. Ecotribology: environmentally acceptable tribological practices, Tribology International 39(8): 728-733. http://dx.doi.org/10.1016/j.triboint.2005.07.002

Cao, Y.; Yu, L.; Liu, W. 2000. Study of the tribological behavior of sulfurized fatty acids as additives in rapeseed oil, Wear 244(1-2): 126-131.

http://dx.doi.org/10.1016/S0043-1648(00)00445-2

CEC. 1995. Biodegradability of Two-Stroke Cycle Outboard Engine Oils in Water. CEC L-33-A-93. Coordinating European Council for the Development of Performance Tests for Transportation Fuels, Lubricants and Other Fluids, Brussels.

DIN 51350-3:2015-03. Prüfung von Schmierstoffen - Prüfung im Vierkugel-Apparat - Teil 3: Bestimmung von Verschleißkennwerten flüssiger Schmierstoffe [Testing of Lubricants - Testing in the Four-Ball Tester - Part 3: Determination of Wearing Characteristics of Liquid Lubricants] (in German).

EN ISO 3104+AC:2000. Petroleum Products - Transparent and Opaque Liquids - Determination of Kinematic Viscosity and Calculation of Dynamic Viscosity.

EN ISO 660:2009. Animal and Vegetable Fats and Oils - Determination of Acid Value and Acidity.

Erhan, S. Z.; Perez, J. M. 2002. Biobased Industrial Fluids and Lubricants. AOCS Publishing. 128 p. 
Honary, L.; Richter, E. 2011. Biobased Lubricants and Greases: Technology and Products. Wiley. 238 p.

ISO 2909:2002. Petroleum Products - Calculation of Viscosity Index from Kinematic Viscosity.

Kodali, D. R. 2002. High performance ester lubricants from natural oils, Industrial Lubrication and Tribology 54(4): 165-170. http://dx.doi.org/10.1108/00368790210431718

Kreivaitis, R.; Gumbyte, M.; Kazancev, K.; Padgurskas, J.; Makareviciene, V. 2013. A comparison of pure and natural antioxidant modified rapeseed oil storage properties, Industrial Crops and Products 43: 511-516.

http://dx.doi.org/10.1016/j.indcrop.2012.07.071

Kreivaitis, R.; Padgurskas, J.; Jankauskas, V.; Kupčinskas, A.; Makarevičienè, V.; Gumbytė, M. 2009. Tribological behavior of rapeseed oil mixtures with mono- and diglycerides, Mechanika (5): 74-78.

Menezes, P. L.; Lovell, M. R.; Kabir, M. A.; Higgs, C. F.; Rohatgi, P. K. 2012. Green lubricants: role of additive size, in M. Nosonovsky, B. Bhushan (Eds.). Green Tribology: Biomimetics, Energy Conservation and Sustainability, 265-286. http://dx.doi.org/10.1007/978-3-642-23681-5_10

O'Brien, R. D. 2008. Fats and Oils: Formulating and Processing for Applications. CRC Press. 680 p.

Padgurskas, J.; Rukuiža, R.; Kreivaitis, R.; Asadauskas, S. J.; Bražinskiene, D. 2009. Tribologic behaviour and suspension stability of iron and copper nanoparticles in rapeseed and mineral oils, Tribology - Materials, Surfaces \& Interfaces 3(3): 97-102. http://dx.doi.org/10.1179/175158309X12560424605196

Sathwik Chatra, K. R.; Jayadas, N. H.; Kailas, S. V. 2012. Natural oil-based lubricants, in M. Nosonovsky, B. Bhushan (Eds.). Green Tribology: Biomimetics, Energy Conservation and Sustainability, 287-328. http://dx.doi.org/10.1007/978-3-642-23681-5_11

Suzuki, A.; Ulfiati, R.; Masuko, M. 2009. Evaluation of antioxidants in rapeseed oils for railway application, Tribology International 42(6): 987-994.

http://dx.doi.org/10.1016/j.triboint.2009.02.001

Zhan, W.; Song, Y.; Ren, T.; Liu, W. 2004. The tribological behaviour of some triazine-dithiocarbamate derivatives as additives in vegetable oil, Wear 256(3-4): 268-274. http://dx.doi.org/10.1016/S0043-1648(03)00372-7 